\title{
Perturbation analysis of thermophoresis, hall current and heat source on flow dissipative aligned convective flow about an inclined plate
}

\author{
G. Dharmaiah ${ }^{1}$, O.D. Makinde ${ }^{2}$, K.S. Balamurugan ${ }^{3}$ \\ ${ }^{I}$ Department of Mathematics, Narasaraopeta Engineering College, Yellamanda, Narasaraopet, A.P., \\ 522601, India. \\ ${ }^{2}$ Faculty of Military Science, Stellenbosch University, Private Bag X2, Saldanha 7395, South Africa. \\ ${ }^{3}$ Department of Mathematics, RVR \& JC College of Engineering, Chowdavaram, Guntur, A.P., \\ 522019, India.
}

Received: 2 December 2019; Received in revised form: 30 December 2019; Accepted: 28 January 2020; Published online: 15 February 2020

(C) Published at www.ijtf.org

\begin{abstract}
This present examination researches the impacts of thermophoresis, heat source and Hall current on dissipative adjusted MHD joint convection stream about an inclined plate inserted in a permeable medium. Utilizing dimensionless variables, the system of partial differential equations is changed into dimensionless equations. By making use of perturbation technique, estimated solutions for velocity, temperature, concentration profiles, skin friction, rate of heat transfer and rate of mass transfer have been determined. The attained results are explained with an assistance of diagrams to examine the impact of distinct parameters such as Magnetic parameter $(\mathrm{M})$, Aligned magnetic parameter $(\xi)$, Schmidt number $(\mathrm{Sc})$, Eckert number $(\mathrm{Ec})$, inclined angle $(\alpha)$, Prandtl number (Pr), heat generation parameter (Q), and chemical reaction $(\mathrm{Kr})$, assuming two cases viz. Case I: $\mathrm{Gr}<0, \mathrm{Gm}<0$ (flow on heated plate); Case II: when $\mathrm{Gr}>0, \mathrm{Gm}>0$ (flow on cooled plate). Additionally, the impacts of the appropriate parameters on the skin-friction coefficient and rates of heat and mass transfer are numerically furnished in tabular form. Skin friction coefficients are firmly diminished as magnetic field rises. Sherwood and Nusselt numbers boost up as enhance in chemical reaction.
\end{abstract}

Keywords: Hall effect, Joule Dissipation, porous medium, inclined plate, perturbation technique, Heat source.

\section{Introduction}

Magnetohydrodynamics becomes important in distinct engineering applications, such as, soil-sciences, MHD generator and nuclear power cooling liquid metal reactors with designing. The mechanism of conduction in ionized gases in the presence of a strong magnetic field is different from that in a metallic substance. The electric current in ionized gases is usually carried out by electrons which undergo successive collisions with other 


\section{Dharmaiah et al.}

International Journal of Thermofluid Science and Technology (2020), Volume 7, Issue 1, Paper No. 20070103

charged or neutral particles. It is to be noted that in the ionized gases, the current is proportional to the applied potential only when the electric field is very weak. However, in the presence of a strong electric field, the electrical conductivity is explicitly affected by the magnetic field. As a result of that, the conductivity parallel to the electric field is reduced. So, the current is reduced to the direction normal to both electric and magnetic fields. This phenomenon is known as the Hall effect (Cowling [29]). Pop [1] examined the effect of Hall currents on hydromagnetic flow near an accelerated plate. An Investigations of Soret, Joule and Hall effects on MHD rotating mixed convective flow past an infinite vertical porous plate analyzed by veerakrishna et al. [2]. A Hall and slip effect on MHD flow through porous medium was presented by Veera Krishna and Chamkha [3]. Nayak [4] studied the radiative stretched flow of convective magnetic field. Jitendra Kumar Singh et al. [5] reported an Impact of time varying wall temperature and concentration on MHD free convective flow of a rotating fluid due to moving free-stream with hall and ion-slip currents. Vaidya et al. [6] studied on the effects of Thermo capillarity on the Thin Film Flow of MHD UCM Fluid over an Unsteady Elastic Surface with Convective Boundary Conditions.

\begin{tabular}{|ll}
\hline \multicolumn{2}{|l}{ Nomenclature } \\
$\mathrm{B}_{0}$ & $\begin{array}{l}\text { Magnetic field coefficient } \\
\text { viscosity of the fluid }\left(\mathrm{wbm}^{-2}\right)\end{array}$ \\
$C_{p}$ & $\begin{array}{l}\text { Specific heat of the fluid at } \\
\text { constant pressure }\left(\mathrm{Jkg}^{-1} \mathrm{~K}^{-1}\right)\end{array}$ \\
$C_{\infty}$ & Concentration far away from the plate \\
$\mathrm{D}_{1}$ & Coefficient of thermal diffusivity \\
$\mathrm{g}$ & Acceleration due to gravity $\left(\mathrm{ms}^{-2}\right)$ \\
$\mathrm{Gr}$ & Grashoff number for heat transfer \\
$\mathrm{Gm}$ & Grashoff number of mass transfer \\
$\mathrm{k}$ & Thermal conductivity of the fluid \\
$K^{*}$ & The permeability of porous medium $\left(\mathrm{m}^{2}\right)$ \\
$\mathrm{K}_{1}$ & Chemical reaction rate constant \\
$\mathrm{Kr}$ & Chemical reaction parameter \\
$\mathrm{Sc}$ & Schmidt number \\
$\mathrm{T}_{\mathrm{W}}$ & Temperature near the plate $(\mathrm{K})$ \\
$T_{\infty}$ & Temperature far away from the plate $(\mathrm{K})$
\end{tabular}

\section{Greek Symbols}

$\phi \quad$ Dimensionless concentration

$\rho \quad$ Fluid density

$\xi \quad$ Aligned magnetic parameter

$\theta \quad$ Dimensionless temperature

$\beta^{*} \quad$ Coefficient of mass expansion

'(Super script) refers differentiation w.r.t. ' $y$ '
$\mathrm{C}_{\mathrm{w}}$ Concentration near the plate
$C^{*}$ Concentration of the fluid
D Chemical molecular diffusivity
Ec Eckert number
m Hall current parameter
M Hartmann number
NuNusselt number
Pr Prandtl number
Q Heat generation parameter
ShSherwood number
So Soret number
$\mathrm{T}^{*}$ Temperature of the fluid
$v_{0}$ Constant suction velocity
$u^{*}, v^{*}$ Velocity components in the $x^{*}$ and $y^{*}$ directions $(\mathrm{m} / \mathrm{s})$

$\beta$ Coefficient of thermal expansion

$\tau$ Skin-friction coefficient

$\alpha$ Inclined angle

$v$ kinematic viscosity of the fluid

$\mu$ Viscosity of the fluid

As of late, mixed convection flows with hall current, chemically reactive heat transfer have mobilized some concentration, along with viscous dissipation and Ohmic (Joule) 
Dharmaiah et al.

International Journal of Thermofluid Science and Technology (2020), Volume 7, Issue 1, Paper No. 20070103

heating has also prominent these days, in applications of materials fabrication operations. The impacts of viscous dissipation and Ohmic heating are normally described by the Eckert number; magnetic parameter and the product of the Eckert number. Chen [7] studied that combined effects of Joule heating and viscous dissipation on Magnetohydrodynamic flow past a permeable surface. Siva Reddy and Raju [8] examined Soret effect on unsteady MHD free convective flow past a semi infinite vertical plate in the presence of viscous dissipation. Satyanarayana et al. [9] reported viscous dissipation and thermal radiation effects on unsteady MHD convection flow past a semi infinite vertical permeable moving porous plate. Dharmaiah et al. [10] analyzed viscous dissipation effect on transient aligned magnetic free convective flow past and inclined moving plate. Heat generation influences may change the temperature, accordingly influencing semiconductor wafers and electronic chips. Chamkha and Ahmed [11] analyzed a unsteady MHD porous flow in the presence of heat generation/ absorption and chemical reaction. Hady et al. [12] studied on MHD free convection flow along a vertical wavy surface with heat generation or absorption effect. Ravikumar et al. [13] examined heat and mass transfer effects on MHD flow of viscous fluid through nonhomogeneous porous medium in presence of temperature dependent heat source.

The thermophoresis effect is of a slighter magnitude order and is frequently ignored in heat-mass transfer performing. Be that as it may, the thermophoresis effect, has been used by way of illustration, for isotope separation and in mixtures between gases with exceptionally lesser molecular weight $(\mathrm{H} 2, \mathrm{He})$. Recently, exponential development of natural convection thermal diffusion flows has turned out to be one of most rapidly developed research fields. Turkyilmazoglu and Pop [14] examined the effects of Soret and heat source on the unsteady radiative MHD free convection flow from an impulsively started infinite vertical plate. Gnaneswara Reddy [15] presented that the effects of thermophoresis, viscous dissipation and joule heating on steady MHD heat and mass transfer flow over an inclined radiative isothermal permeable surface with variable thermal conductivity. Jayaraj [16] analyzed that the effect of thermophoresis in laminar flow over cold inclined plate.

As of late, combined heat-mass transfer problems as well as chemical reaction through porous medium are of prominence in numerous actions acknowledged, wide-ranging proportion appraised. In procedures, for example, evaporation at the surface of a water body and the flow in a desert cooler, heat-mass transfer occur all the while in chemical reaction. VeeraKrishna [17] examined that a hall effects on MHD flow of a visco-elastic fluid through a porous medium over an infinite oscillating porous plate with heat source and chemical reaction. Kandasamy et al. [18] presented Lie group analysis for the effect of temperature dependent fluid viscosity with thermophoresis and chemical reaction on MHD free convective heat and mass transfer over a porous stretching surface in the presence of heat source / sink. Pal and Talukdar [19] studied a perturbation analysis of unsteady magnetohydrodynamic convective heat and mass transfer chemical reaction. BabyRani et al. [20] explained an MHD transient free convection aligned magnetic and chemically reactive flow past a porous inclined plate. Balamurugan et al. [21] exposed an influence of radiation absorption, viscous and joules dissipation on mhd free convection chemically reactive and radiative flow in a moving inclined porous plate with temperature dependent heat source. Uddin et al. [22] reported on numerical simulation of convective heat transport within the nanofluid filled vertical tube of plain and uneven side walls. Severno and Campo [23] studied a finite strip method applied to steady heat conduction and thermal radiation in a planar slab: absorbing- emitting gray material and parallel diffuse surfaces. Manjunatha et al. [24] exposed on peristaltic flow of a Jeffery fluid over a porous conduit in the presence of variable 
Dharmaiah et al.

International Journal of Thermofluid Science and Technology (2020), Volume 7, Issue 1, Paper No. 20070103

liquid properties and convective boundary conditions. Nayaket al. [25] explained an impact of non-uniform heat source/sink and variable viscosity on mixed convection flow over an inclined plate. Shankar et al [26] examined a mass transfer effects on mhd flow through porous medium past an exponentially accelerated inclined plate with variable temperature and thermal radiation. Ramprasad et al. [27] examined an unsteady MHD convective heat and mass transfer flow past an inclined moving surface with heat absorption. Reddy et al.[28] studied a thermo-diffusion and chemical effects with simultaneous thermal and mass diffusion in MHD mixed convection flow with ohmic heating.

Motivated by the above studies, in this paper we have considered hall current, aligned magnetic and ohmic heating effects on an steady simultaneous convective heat and mass transfer flow of an incompressible, electrically conducting, heat generating/absorbing fluid along a semi-infinite inclined porous plate embedded in a porous medium with the presence of chemical reaction and soret effects. The novelty of this study is the consideration of a double diffusion fluid (mass diffusion and as we as thermal diffusion) along with chemical reaction and heat source through a inclined porous plate in a conducting filed. In spite of that many authors contributed similar works; still there are many interesting aspects to be concentrated. Hence authors are interested to carry on this investigation. For the validity of our work we have compared our results with the existing results of Reddy et al. [25] in the absence of inclined angle, aligned and hall current, porous medium, ohmic heating and heat source. Our result appears to be in excellent agreement with the existing results.

\section{Formulation and solution of the problem}

The Hall effects on the joint convection permeable flow of a dissipative viscous fluid about an inclined plate in the presence of heat source and Soret effects. We assumed that the Cartesian co-ordinate system such that $x^{*}, y^{*}$ axes are assumed along the plate in upward direction and normal to it respectively (Fig. 1). A transverse constant magnetic field, in the direction of $y^{*}$ - axis is applied. In view of the motion is two dimensional and length of the plate is large therefore all variables are independent of $x^{*}$. The governing equations of continuity, momentum, energy and mass for electrically conducting flow fluid are specified by the following:

Equation of Continuity:

$$
\frac{\partial v^{*}}{\partial y^{*}}=0 \Rightarrow v^{*}=-v_{0}\left(v_{0}>0\right)
$$

Equation of Motion:

$$
v^{*} \frac{d u^{*}}{d y^{*}}=v \frac{d^{2} u^{*}}{d y^{* 2}}+g \beta\left(T^{*}-T_{\infty}\right) \cos \alpha+g \beta^{*}\left(C^{*}-C_{\infty}\right) \cos \alpha-\frac{\sin ^{2} \xi}{\left(1-m^{2}\right)} \frac{\sigma B_{0}^{2}}{\rho} u^{*}-\frac{v}{K^{*}} u^{*}
$$

Equation of Energy:

$$
v^{*} \frac{d T^{*}}{d y^{*}}=\frac{k}{\rho C_{p}} \frac{d^{2} T^{*}}{d y^{*^{2}}}+\frac{Q_{h}}{\rho C_{p}}\left(T^{*}-T_{\infty}\right)+\frac{v}{C_{p}}\left(\frac{d u^{*}}{d y^{*}}\right)^{2}+\frac{\sin ^{2} \xi}{\left(1-m^{2}\right)^{2}} \frac{\sigma B_{0}^{2}}{\rho C_{p}} u^{*^{2}}+\frac{v}{\rho C_{p}} u^{*^{2}}
$$

Equation of Mass Transfer: 
Dharmaiah et al.

International Journal of Thermofluid Science and Technology (2020), Volume 7, Issue 1, Paper No. 20070103

$v^{*} \frac{d C^{*}}{d y^{*}}=D \frac{d^{2} C^{*}}{d y^{* 2}}-K_{1}\left(C^{*}-C_{\infty}\right)+D_{1} \frac{d^{2} T^{*}}{d y^{* 2}}$

The relevant boundary conditions are

$$
\begin{aligned}
& u^{*}=0 ; \quad T^{*}=T_{w} ; \quad C^{*}=C_{w} \quad \text { at } y^{*}=0 \\
& u^{*} \rightarrow 0 ; \quad T^{*} \rightarrow T_{\infty} ; \quad C^{*} \rightarrow C_{\infty} \quad \text { as } y^{*} \rightarrow \infty
\end{aligned}
$$

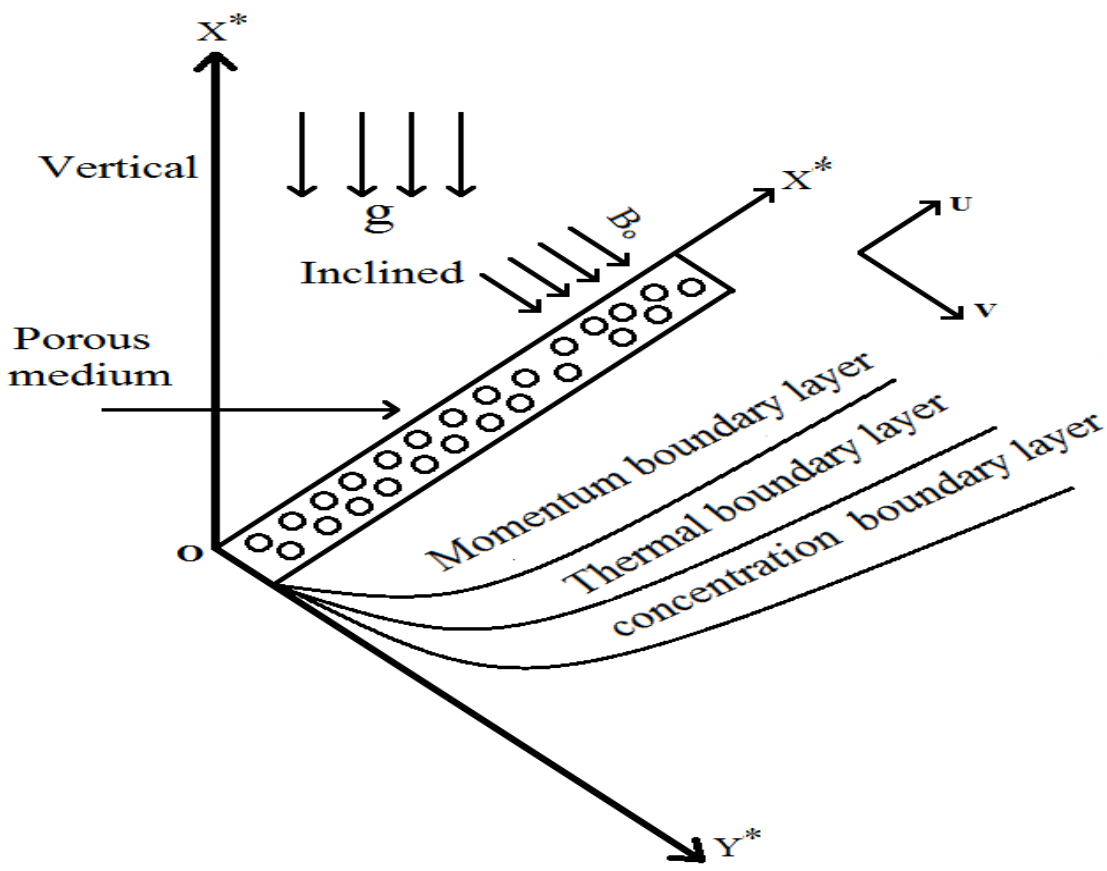

Fig. 1. Flow configuration and coordinate system.

R.H.S. of an equation (2), $2^{\text {nd }}$ and $3^{\text {rd }}$ terms are called inclined convective, $4^{\text {th }}$ term is called aligned with Hall Effect and $5^{\text {th }}$ term is called porous effect. R.H.S. of an equation (3), second term is heat source, third term is viscous dissipation and fourth term is joule effect. R.H.S. of an equation (4), $2^{\text {nd }}$ term is chemical reaction and $3^{\text {rd }}$ term is Soret effect.

Non-dimensional quantities are

$$
\begin{aligned}
& y=\frac{y^{*} v_{0}}{v}, u=\frac{u^{*}}{v_{0}}, \operatorname{Pr}=\frac{v \rho C_{p}}{k}, \theta=\frac{T^{*}-T_{\infty}}{T_{w}-T_{\infty}}, \phi=\frac{C^{*}-C_{\infty}}{C_{w}-C_{\infty}}, K^{*}=\frac{K v^{2}}{v_{0}^{2}}, v=\frac{\mu}{\rho}, S c=\frac{v}{D}, \\
& G r=\frac{v g \beta\left(T_{w}-T_{\infty}\right)}{v_{0}^{3}}, G m=\frac{v g \beta^{*}\left(C_{w}-C_{\infty}\right)}{v_{0}^{3}}, E c=\frac{\rho C_{p}}{C_{p}\left(T_{w}-T_{\infty}\right)}, M^{2}=\frac{\sigma B_{0}^{2} v}{\rho v_{0}^{2}}, S o=\frac{D_{1}\left(T_{w}-T_{\infty}\right)}{v\left(C_{w}-C_{\infty}\right)}, \\
& K r=\frac{v k_{1}}{v_{0}^{2}}, Q=\frac{Q_{h} v}{\rho C_{p} v_{0}^{2}}
\end{aligned}
$$

Obtained dimension form of eqs. (2)-(4) are

$u^{\prime \prime}+u^{\prime}-\left(\frac{\sin ^{2} \xi}{1-m^{2}} M^{2}+\frac{1}{K}\right) u=-G r \theta \cos \alpha-G m \phi \cos \alpha$ 
Dharmaiah et al.

International Journal of Thermofluid Science and Technology (2020), Volume 7, Issue 1, Paper No. 20070103

$\theta^{\prime \prime}+\operatorname{Pr} \theta^{\prime}+\operatorname{Pr} Q \theta=-\operatorname{Pr} E c\left(u^{\prime}\right)^{2}-\operatorname{Pr} E c\left[\frac{\sin ^{2} \xi}{\left(1-m^{2}\right)^{2}} M^{2}+\frac{1}{K}\right] u^{2}$

$\phi^{\prime \prime}+S c \phi^{\prime}-S c K r \phi=-S o S c \theta^{\prime \prime}$

Reduced appropriate boundary conditions are

$u=0, \theta=1, \phi=1 \quad$ at $\quad y=0$

$u \rightarrow 0, \theta \rightarrow 0, \phi \rightarrow 0 \quad$ as $y \rightarrow \infty$

The substantial variables $\mathrm{u}(\mathrm{y}), \theta(\mathrm{y}), \phi(\mathrm{y})$ may be stretched within the power of Eckert number (Ec). This could be potential physically as Ec for the flow of associate incompressible fluid continuously is a smaller amount unity. It may be taken physically because the flow due to the joule dissipation is super imposed on the main flow.

Therefore we assumed as:

$u(y)=u_{0}(y)+E c u_{1}(y)+O\left(E c^{2}\right)$
$\theta(y)=\theta_{0}(y)+E c \theta_{1}(y)+O\left(E c^{2}\right)$
$\phi(y)=\phi_{0}(y)+E c \phi_{1}(y)+O\left(E c^{2}\right)$

Use in preference to equations (13)-(15) in equations (8)-(10) and comparing the coefficients of identical powers of Ec, we have

$$
\begin{aligned}
& u_{0}^{\prime \prime}+u_{0}^{\prime}-\left(\frac{\sin ^{2} \xi}{\left(1-m^{2}\right)} M^{2}+\frac{1}{K}\right) u_{0}=-G r \theta_{0} \cos \alpha-G m \phi_{0} \cos \alpha \\
& u_{1}^{\prime \prime}+u_{1}^{\prime}-\left(\frac{\sin ^{2} \xi}{\left(1-m^{2}\right)} M^{2}+\frac{1}{K}\right) u_{1}=-G r \theta_{1} \cos \alpha-G m \theta_{1} \cos \alpha \\
& \theta_{0}^{\prime \prime}+\operatorname{Pr} \theta_{0}^{\prime}+\operatorname{Pr} Q \theta_{0}=0 \\
& \theta_{1}^{\prime \prime}+\operatorname{Pr} \theta_{1}^{\prime}+\operatorname{Pr} Q \theta_{1}=-\operatorname{Pr} u_{0}^{\prime 2}-\operatorname{Pr}\left(\frac{\sin ^{2} \xi}{\left(1-m^{2}\right)^{2}} M^{2}+\frac{1}{K}\right) u_{0}^{2} \\
& \phi_{0}^{\prime \prime}+\operatorname{Sc} \phi_{0}^{\prime}-\operatorname{ScKr} \phi_{0}=-\operatorname{ScSo} \theta_{0}^{\prime \prime} \\
& \phi_{1}^{\prime \prime}+\operatorname{Pr} \phi_{1}^{\prime}-\operatorname{ScKr} \phi_{1}=-\operatorname{ScSo} \theta_{1}^{\prime \prime}
\end{aligned}
$$

The relevant boundary conditions are

$$
\begin{aligned}
& u_{0}=0, u_{1}=0, \theta_{0}=1, \theta_{1}=0, \phi_{0}=1, \phi_{1}=0 \text { at } y=0 \\
& u_{0} \rightarrow 0, u_{1} \rightarrow 0, \theta_{0} \rightarrow 0, \theta_{1} \rightarrow 0, \phi_{0} \rightarrow 0, \phi_{1} \rightarrow 0
\end{aligned}
$$

Solving equations (16)-(21) with the help of equations (22)-(23), we obtain

$$
\begin{aligned}
& u_{0}(y)=A_{5} e^{-m_{3} y}+A_{3} e^{-m_{1} y}+A_{4} e^{-m_{2} y} \\
& u_{1}(y)=A_{29} e^{-m_{6} y}+A_{21} e^{-m_{5} y}+A_{22} e^{-m_{4} y}+A_{23} e^{-2 m_{3} y}+A_{24} e^{-2 m_{2} y}+A_{25} e^{-2 m_{1} y} \\
& +A_{26} e^{-\left(m_{3}+m_{2}\right) y}+A_{27} e^{-\left(m_{1}+m_{2}\right) y}+A_{28} e^{-\left(m_{3}+m_{1}\right) y} \\
& \theta_{0}(y)=e^{-m_{1} y} \\
& \theta_{1}(y)=A_{12} e^{-m_{4} y}+A_{6} e^{-2 m_{3} y}+A_{7} e^{-2 m_{2} y}+A_{8} e^{-2 m_{1} y}+A_{9} e^{-\left(m_{3}+m_{2}\right) y}+A_{10} e^{-\left(m_{1}+m_{2}\right) y}+A_{11} e^{-\left(m_{1}+m_{3}\right) y}
\end{aligned}
$$


Dharmaiah et al.

International Journal of Thermofluid Science and Technology (2020), Volume 7, Issue 1, Paper No. 20070103

$$
\begin{gathered}
\phi_{0}(y)=A_{2} e^{-m_{2} y}+A_{1} e^{-m_{1} y} \\
\phi_{1}(y)=A_{20} e^{-m_{5} y}+A_{13} e^{-m_{4} y}+A_{14} e^{-2 m_{3} y}+A_{15} e^{-2 m_{2} y}+A_{16} e^{-2 m_{1} y} \\
\quad+A_{17} e^{-\left(m_{2}+m_{3}\right) y}+A_{18} e^{-\left(m_{2}+m_{1}\right) y}+A_{19} e^{-\left(m_{1}+m_{3}\right) y}
\end{gathered}
$$

Substituting (24)-(29) in equations (13)-(15), Obtain distributions on boundary layer as follows:

$$
\begin{aligned}
& \begin{aligned}
u(y) & =u_{0}(y)+E_{c} u_{1}(y) \\
& =\left[A_{5} e^{-m_{3} y}+A_{3} e^{-m_{1} y}+A_{4} e^{-m_{2} y}\right]+E c\left[\begin{array}{l}
A_{29} e^{-m_{6} y}+A_{21} e^{-m_{5} y}+A_{22} e^{-m_{4} y} \\
+A_{23} e^{-\left(2 m_{3}\right) y}+A_{24} e^{-\left(2 m_{2}\right) y}+A_{25} e^{-\left(2 m_{1}\right) y} \\
+A_{26} e^{-\left(m_{2}+m_{3}\right) y}+A_{27} e^{-\left(m_{2}+m_{1}\right) y}+A_{28} e^{-\left(m_{1}+m_{3}\right) y}
\end{array}\right] \\
\theta(y) & =\theta_{0}(y)+E c \theta_{1}(y) \\
& =\left[e^{-m_{1} y}\right]+E c\left[\begin{array}{l}
A_{12} e^{-m_{4} y}+A_{6} e^{-2 m_{3} y}+A_{7} e^{-2 m_{2} y}+A_{8} e^{-2 m_{1} y}+ \\
A_{9} e^{-\left(m_{3}+m_{2}\right) y}+A_{10} e^{-\left(m_{1}+m_{2}\right) y}+A_{11} e^{-\left(m_{3}+m_{1}\right) y}
\end{array}\right]
\end{aligned} \\
& \phi(y)=\phi_{0}(y)+E c \phi_{1}(y) \\
&=\left[A_{2} e^{-m_{2} y}+A_{1} e^{-m_{1} y}\right]+E c\left[\begin{array}{l}
+A_{20} e^{-m_{5} y}+A_{13} e^{-m_{5} y}+A_{13} e^{-m_{4} y}+A_{14} e^{-2 m_{3} y}+A_{15} e^{-2 m_{2} y}+ \\
A_{16} e^{-2 m_{1} y}+A_{17} e^{-\left(m_{3}+m_{2}\right) y}+A_{18} e^{-\left(m_{1}+m_{2}\right) y}+A_{19} e^{-\left(m_{3}+m_{1}\right) y}
\end{array}\right]
\end{aligned}
$$

At the plate, the skin-friction coefficient is

$$
\begin{aligned}
C f & =\left(\frac{\partial u}{\partial y}\right)_{y=0} \\
& =\left[-m_{3} A_{5}-m_{2} A_{4}-m_{1} A_{3}\right]+E c\left[\begin{array}{l}
-m_{6} A_{29}-m_{5} A_{21}-m_{4} A_{22}-2 m_{3} A_{23}-2 m_{2} A_{24}- \\
2 m_{1} A_{25}-\left(m_{3}+m_{2}\right) A_{26}-\left(m_{1}+m_{2}\right) A_{27}-\left(m_{3}+m_{1}\right) A_{28}
\end{array}\right]
\end{aligned}
$$

At the plate, rate of heat transfer is

$$
\begin{aligned}
& N u_{x}=-x \frac{\left(\frac{\partial \theta}{\partial y}\right)_{y=0}}{\left(T_{w}-T_{\infty}\right)} \Rightarrow \frac{N u_{x}}{\operatorname{Re}_{x}}=-\left(\frac{\partial \theta}{\partial y}\right)_{y=0} \\
& =\left[m_{1}\right]+E c\left[\begin{array}{l}
\left(m_{1}+m_{2}\right) A_{10}+\left(m_{3}+m_{2}\right) A_{9}+\left(m_{3}+m_{1}\right) A_{11}+ \\
m_{4} A_{12}+2 m_{3} A_{6}+2 m_{2} A_{7}+2 m_{1} A_{8}
\end{array}\right]
\end{aligned}
$$

At the plate, rate of mass transfer is

$$
\begin{aligned}
& S h_{x}=-x \frac{\left(\frac{\partial \phi}{\partial y}\right)_{y=0}}{\left(C_{w}-C_{\infty}\right)} \Rightarrow \frac{S h_{x}}{\operatorname{Re}_{x}}=-\left(\frac{\partial \phi}{\partial y}\right)_{y=0} \\
& =\left[m_{2} A_{2}+m_{1} A_{1}\right] E c\left[\begin{array}{l}
m_{5} A_{20}+m_{4} A_{13}+2 m_{3} A_{14}+2 m_{2} A_{15}+2 m_{1} A_{16}+ \\
\left(m_{3}+m_{2}\right) A_{17}+\left(m_{1}+m_{2}\right) A_{18}+\left(m_{3}+m_{1}\right) A_{19}
\end{array}\right]
\end{aligned}
$$

\section{Results and Discussion}


Dharmaiah et al.

International Journal of Thermofluid Science and Technology (2020), Volume 7, Issue 1, Paper No. 20070103

In this examination, the accompanying defaulting parameter values are taking up for computations: $\mathrm{Gr}=2, \mathrm{Gm}=4, \mathrm{~K}=0.5, \mathrm{M}=0.5, \mathrm{Pr}=0.71, \mathrm{Ec}=0.01, \mathrm{Sc}=0.45, \mathrm{~S}_{0}=0.1$,

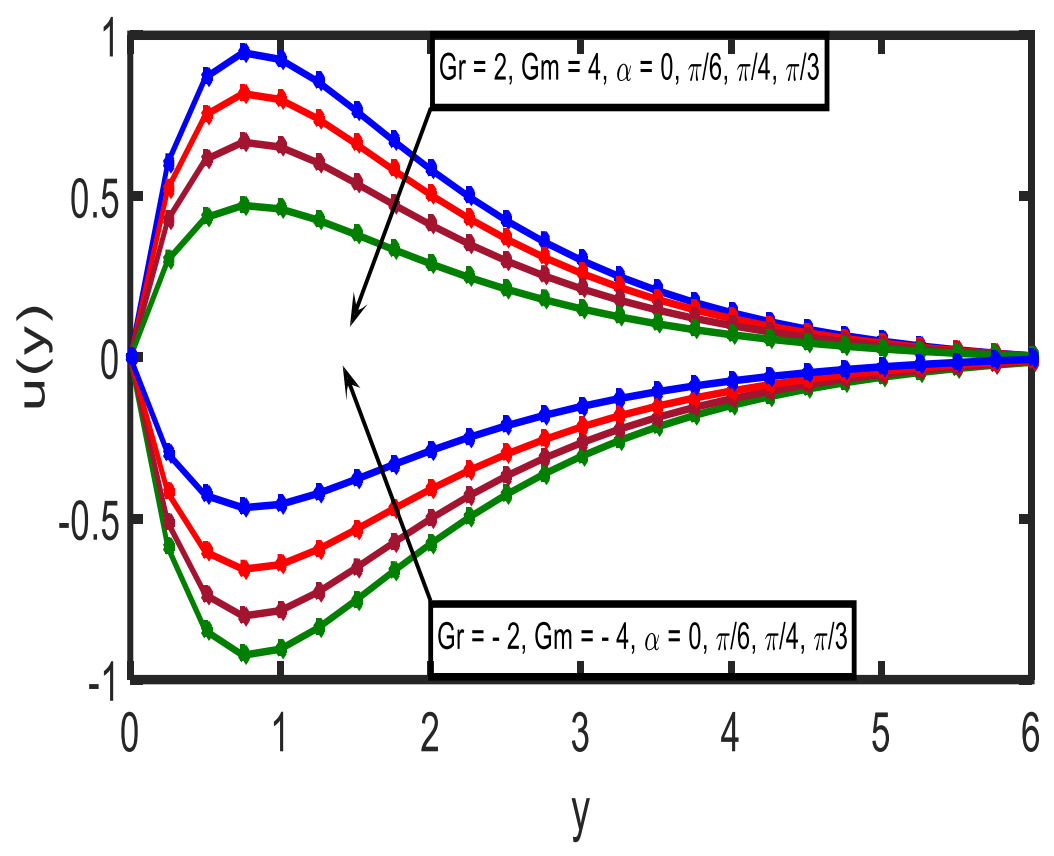

Fig.2 Variations of $\alpha$ on velocity profiles

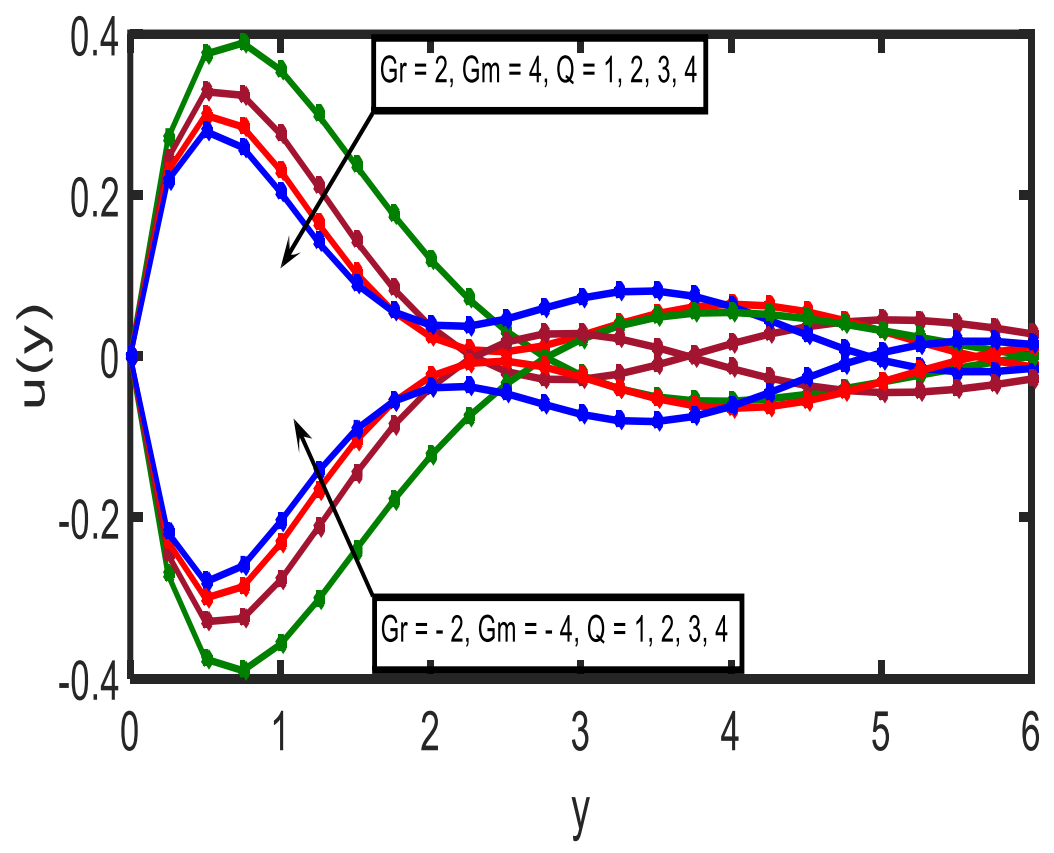

Fig.3 Variations of Q on velocity profiles

$\mathrm{Q}=0.3, \alpha=\pi / 3, \mathrm{~m}=0.1, \xi=\pi / 3$. All graphs in this manner correspond to above values except exclusively indicated in the particular graphs. Figs. (2-15) delineate the velocity, temperature and concentration distributions consequently. Tables (1-3) speak to difference in Skin friction, Nusselt and Sherwood numbers. An influence of inclination of the surface on 
Dharmaiah et al.

International Journal of Thermofluid Science and Technology (2020), Volume 7, Issue 1, Paper No. 20070103

velocity is appeared in Figure 2 . We see that fluid velocity from this figure is decreased for rising angle $\alpha$ with $\mathrm{Gr}=2 \& \mathrm{Gm}=4$ (flow on cooled plate) whereas velocity increases with

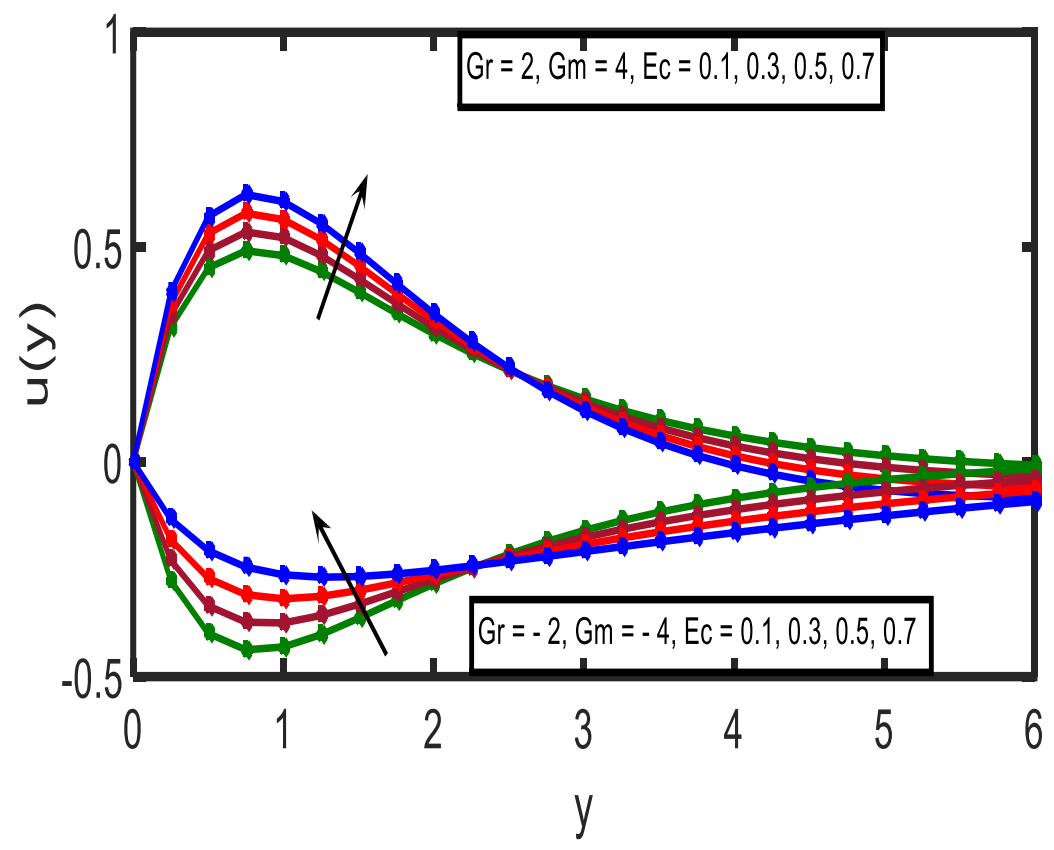

Fig.4 Variations of Ec on velocity profiles

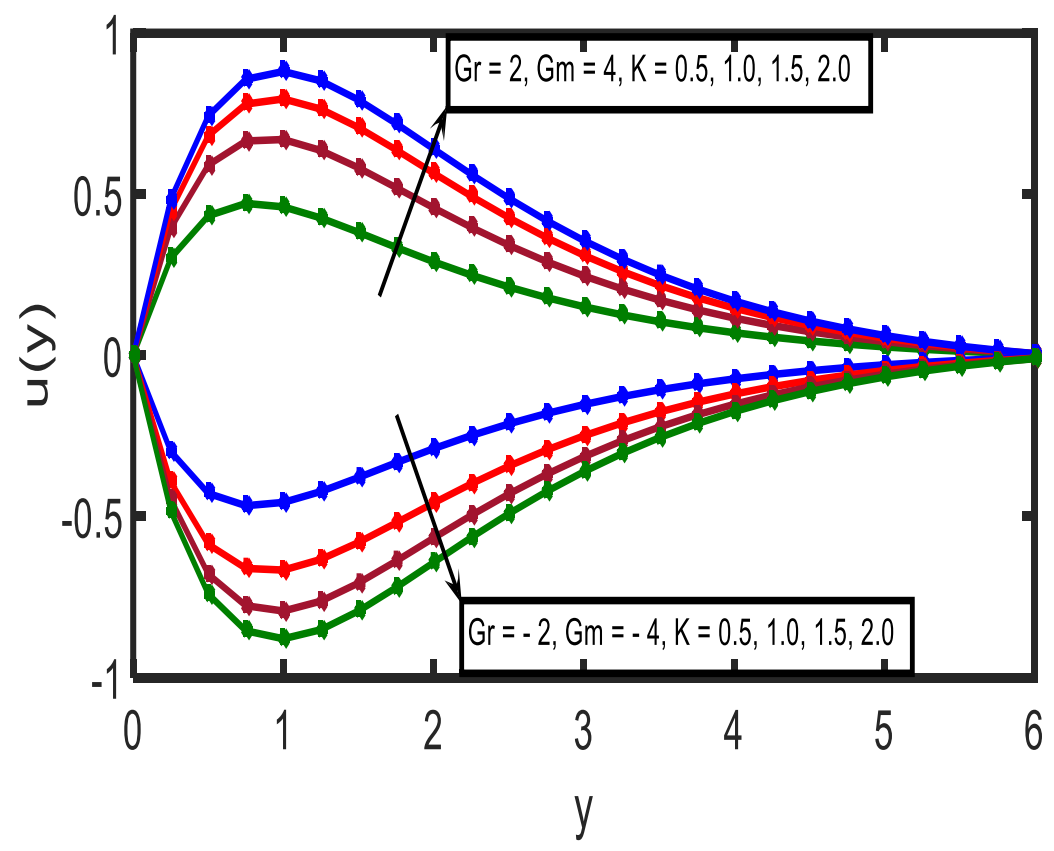

Fig.5 Variations of K on velocity profiles

$\mathrm{Gr}=-2 \& \mathrm{Gm}=-4$ (flow on heated plate). The plate is vertical $(\alpha=0)$, it has greater velocity and as the surface is inclined, the buoyancy effect lessen due to components of gravity $(\mathrm{g} \cos \alpha)$. Variations of $\mathrm{Q}$ on velocity distribution were studied in figure 3 . The results shows, the velocity diminishes as Q decreases and on the other hand enhances the velocity. The impact of Eckert number is appeared in figure 4. The Eckert number demonstrates an 
Dharmaiah et al.

International Journal of Thermofluid Science and Technology (2020), Volume 7, Issue 1, Paper No. 20070103

association between the kinetic energy and the enthalpy, in the flow. Also, Ec encapsulates the viscous fluid stresses by converting kinetic energy into internal energy. More prominent

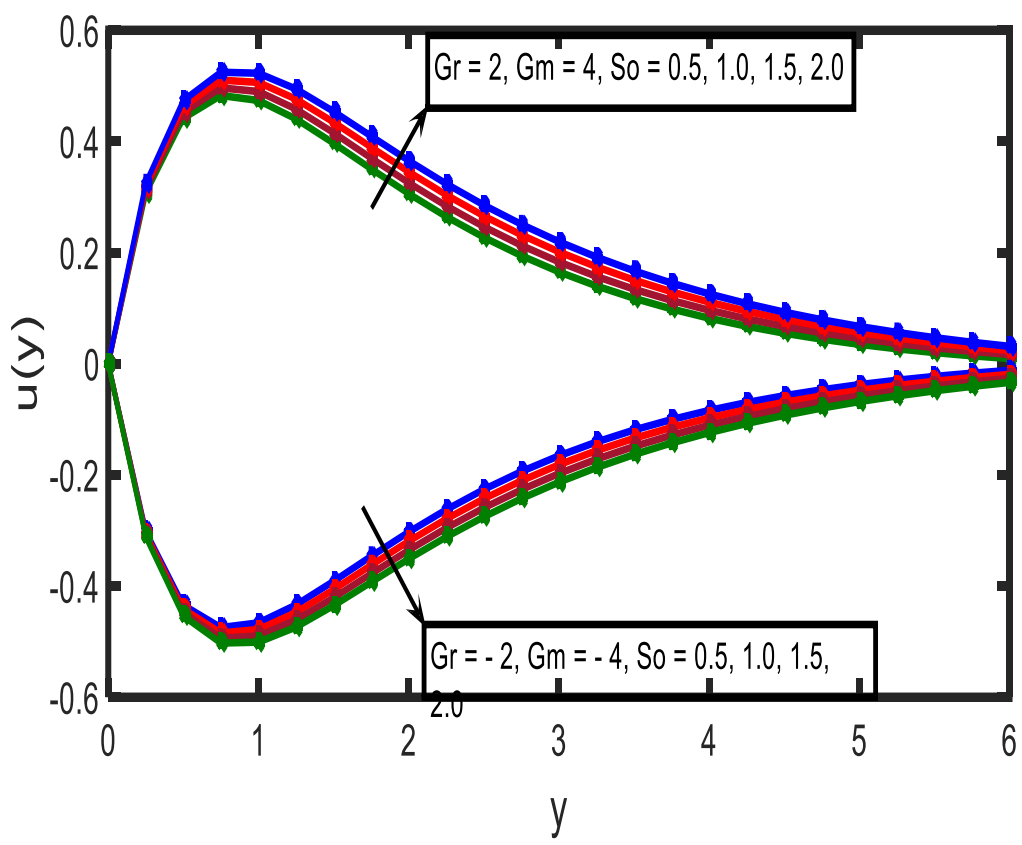

Fig.6 Variations of So on velocity profiles

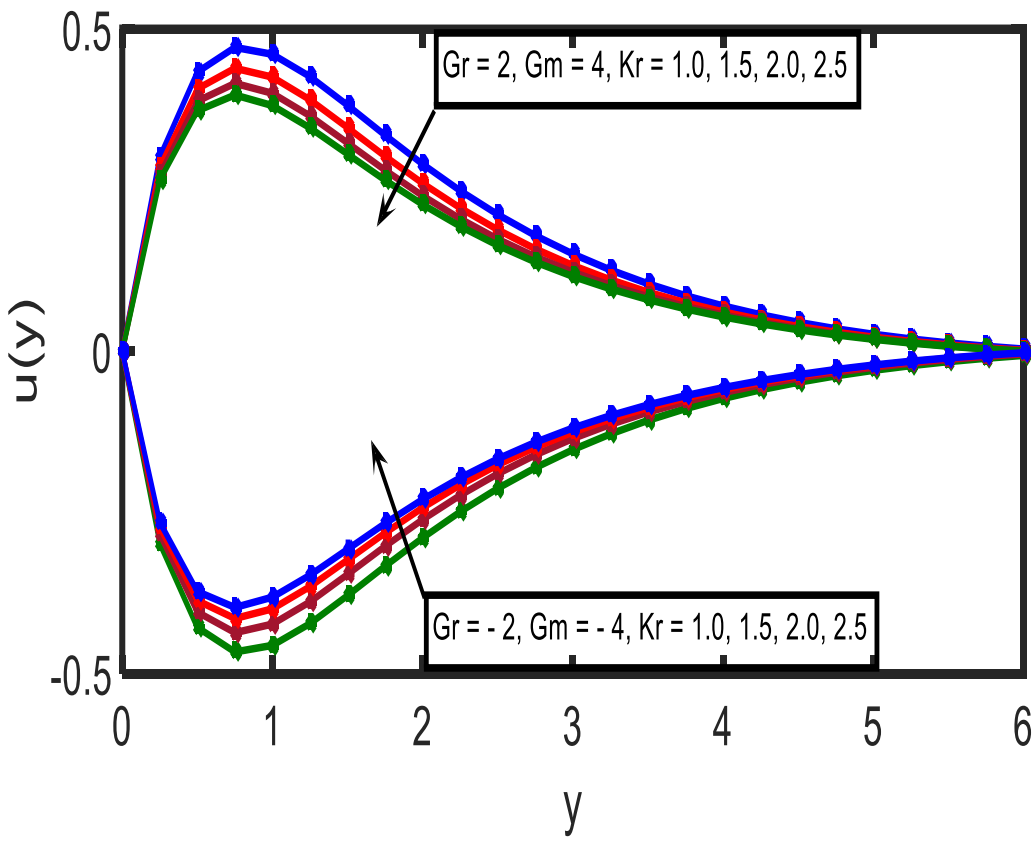

Fig.7 Variations of $\mathrm{Kr}$ on velocity profiles

viscous dissipative heat causes an ascent in temperature, just as velocity and cross flow velocity that is in both heating and cooling of the surface, velocity increases. Variations of permeability parameter on velocity are visualized graphically in Fig. 5. As permeability increases the regime solid fibers progressively decrease. This results in an acceleration in velocity with $\mathrm{Gr}=2 \& \mathrm{Gm}=4$ (flow on cooled plate) and declaration in velocity with $\mathrm{Gr}=$ - 
Dharmaiah et al.

International Journal of Thermofluid Science and Technology (2020), Volume 7, Issue 1, Paper No. 20070103

$2 \& \mathrm{Gm}=-4$ (flow on heated plate). The implication for MHD energy generators is that the flow can be damped strategically via the introduction of a porous material in the flow zone

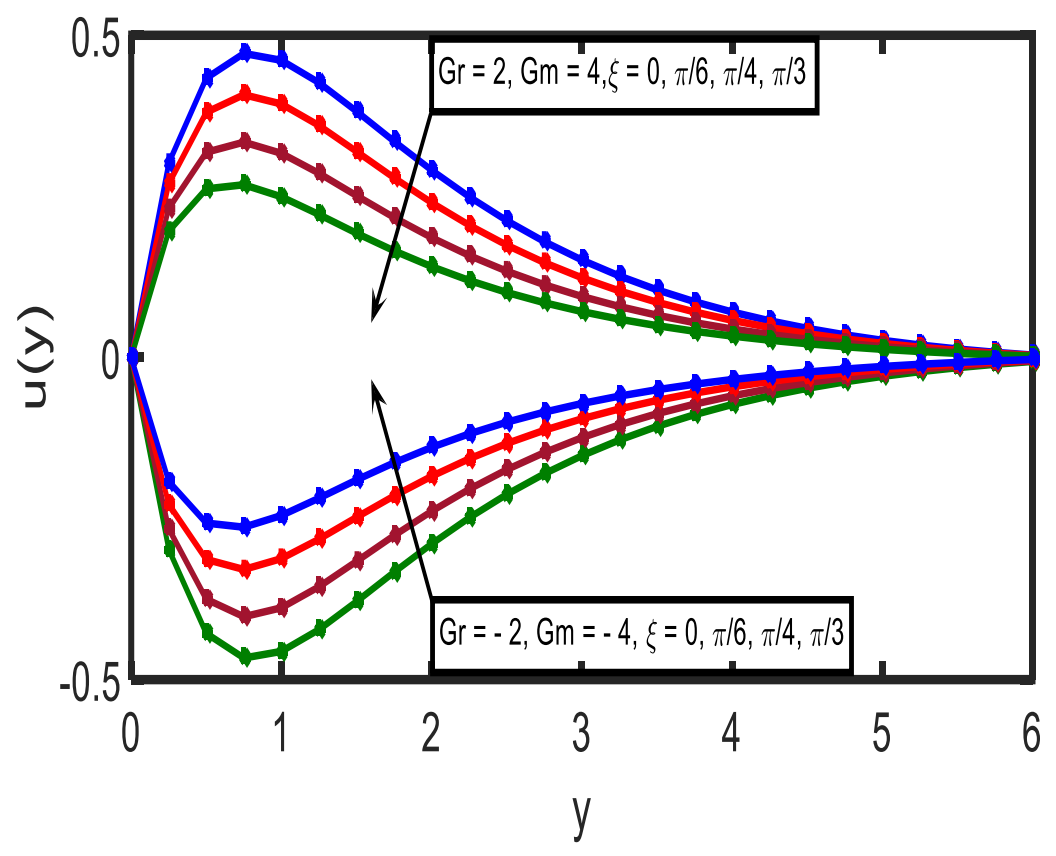

Fig.8 Variations of $\xi$ on velocity profiles

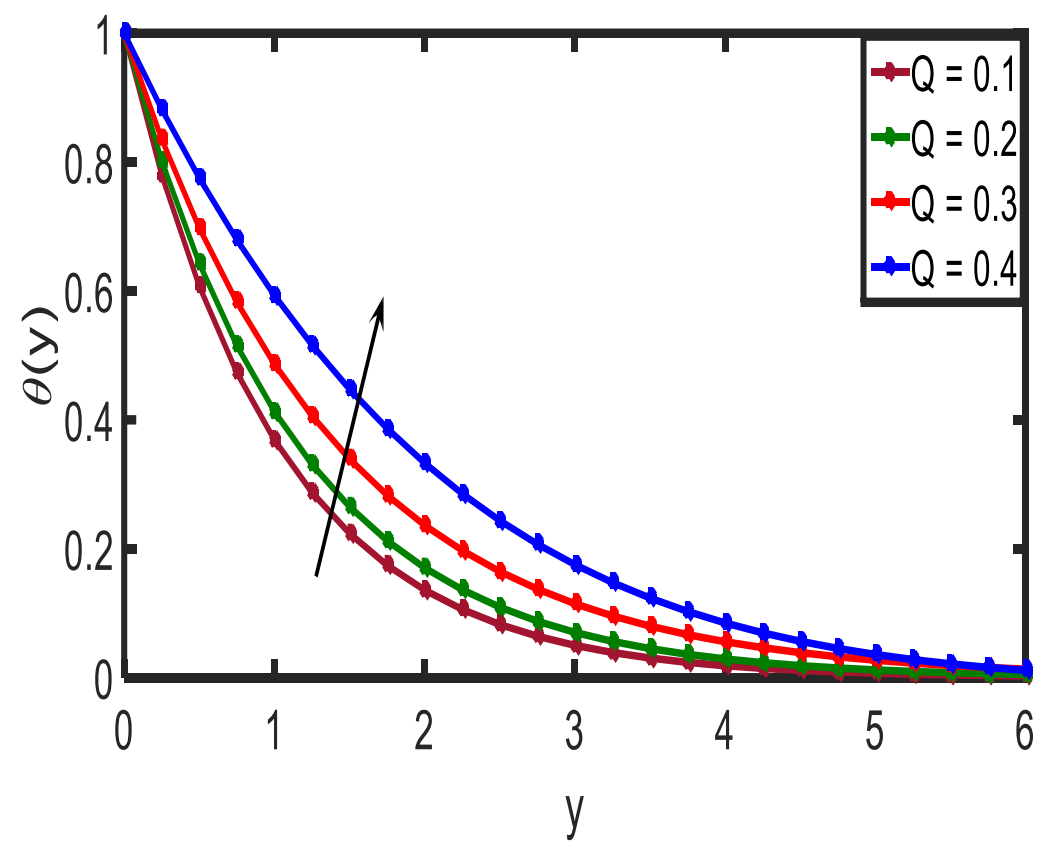

Fig.9 Variations of Q on temperature distribution

and accelerated with higher permeability media. Figure 6 presents the response on velocity distributions for distinct values of So. Executed result is, increasing soret significantly increases with $\mathrm{Gr}=2 \& \mathrm{Gm}=4$ (flow on cooled plate) i.e. accelerates the boundary layer flow but, the velocity accelerates the flow with $\mathrm{Gr}=-2 \& \mathrm{Gm}=-4$ (flow on heated plate). 
Dharmaiah et al.

International Journal of Thermofluid Science and Technology (2020), Volume 7, Issue 1, Paper No. 20070103

For the fixed estimations of different parameters, the influences of chemical reaction parameter $\mathrm{Kr}$ on the dimensionless velocity are illustrated in Fig. 7. Figure 8 shows the

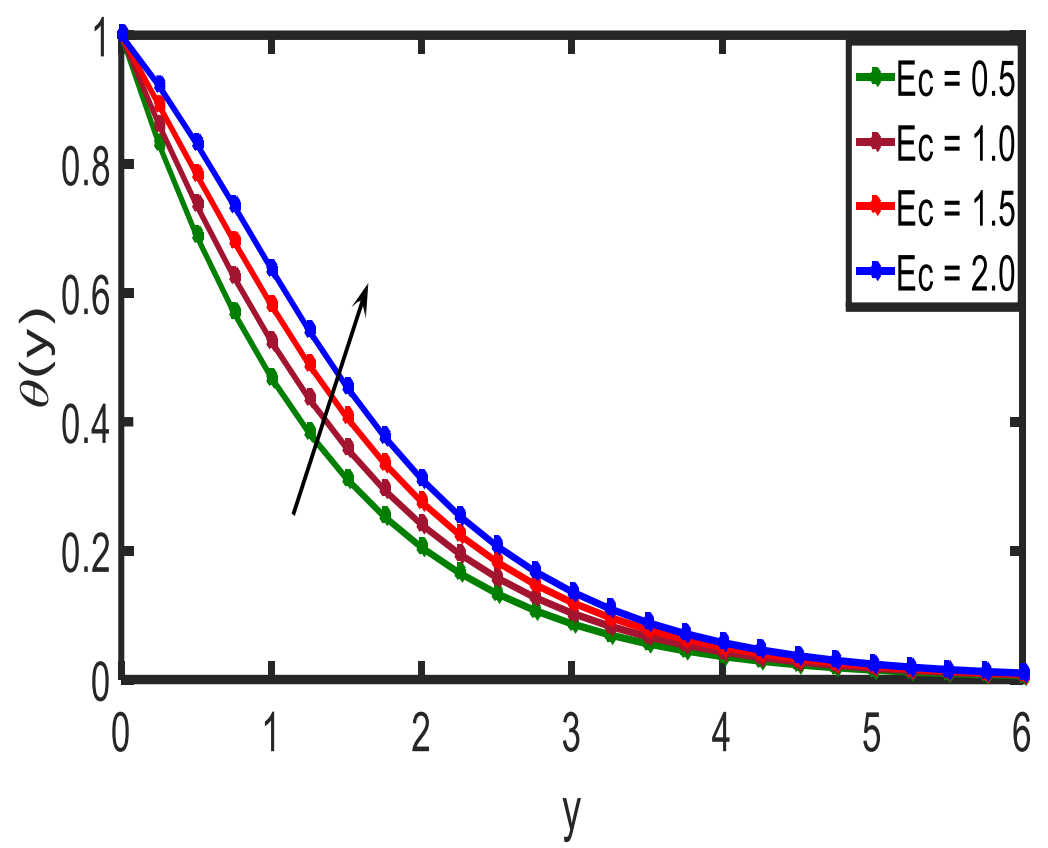

Fig.10 Variations of Ec on temperature distribution

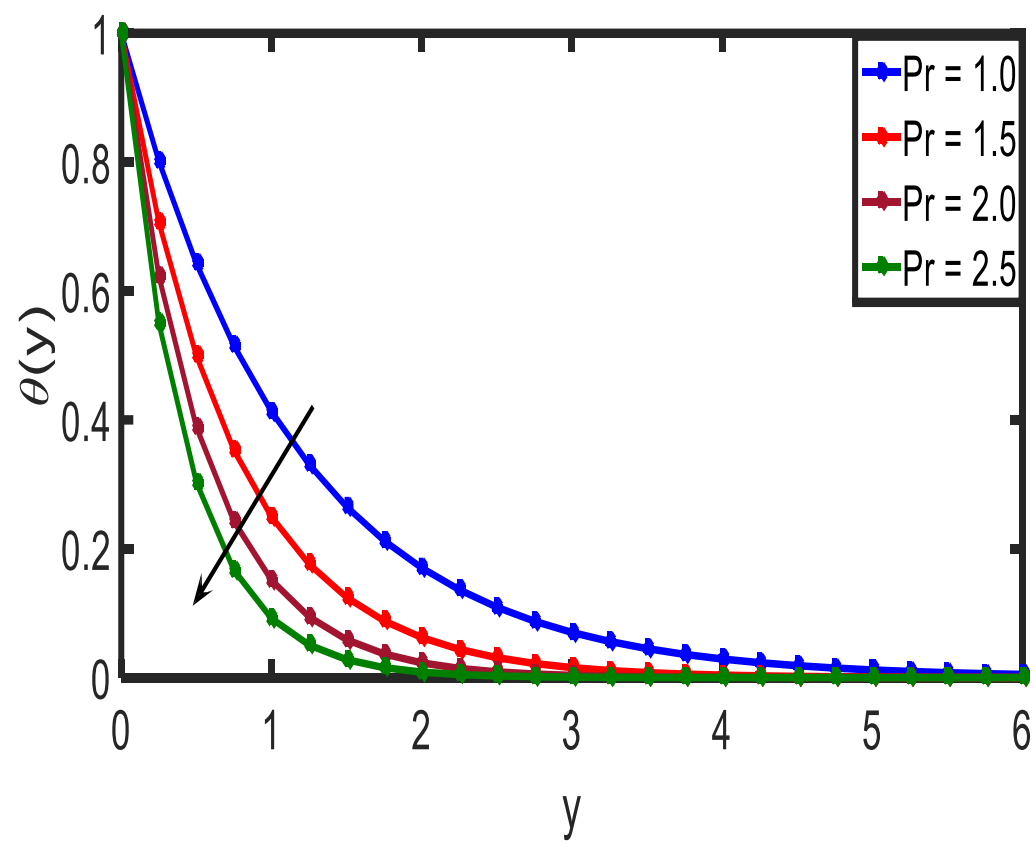

Fig.11 Variations of Pr on temperature distribution

effect of aligned angle over velocity. From these, it is observed that the aligned angle does show very less influence in the velocity such that flow decreases with $\mathrm{Gr}=2$ \& $\mathrm{Gm}=4$ (flow on cooled plate) whereas velocity increases with $\mathrm{Gr}=-2 \& \mathrm{Gm}=-4$ (flow on heated plate). The impact of heat generation parameter $\mathrm{Q}$ on temperature is depicted in Fig. 9. Here, we see that the estimation of $\mathrm{Q}$ enhances, the temperature component also rises along 
Dharmaiah et al.

International Journal of Thermofluid Science and Technology (2020), Volume 7, Issue 1, Paper No. 20070103

the boundary layer. Eckert number variations on temperature component are illustrated in Fig. 10. Clearly the temperature component that are illustrated in figure 10, increased due to

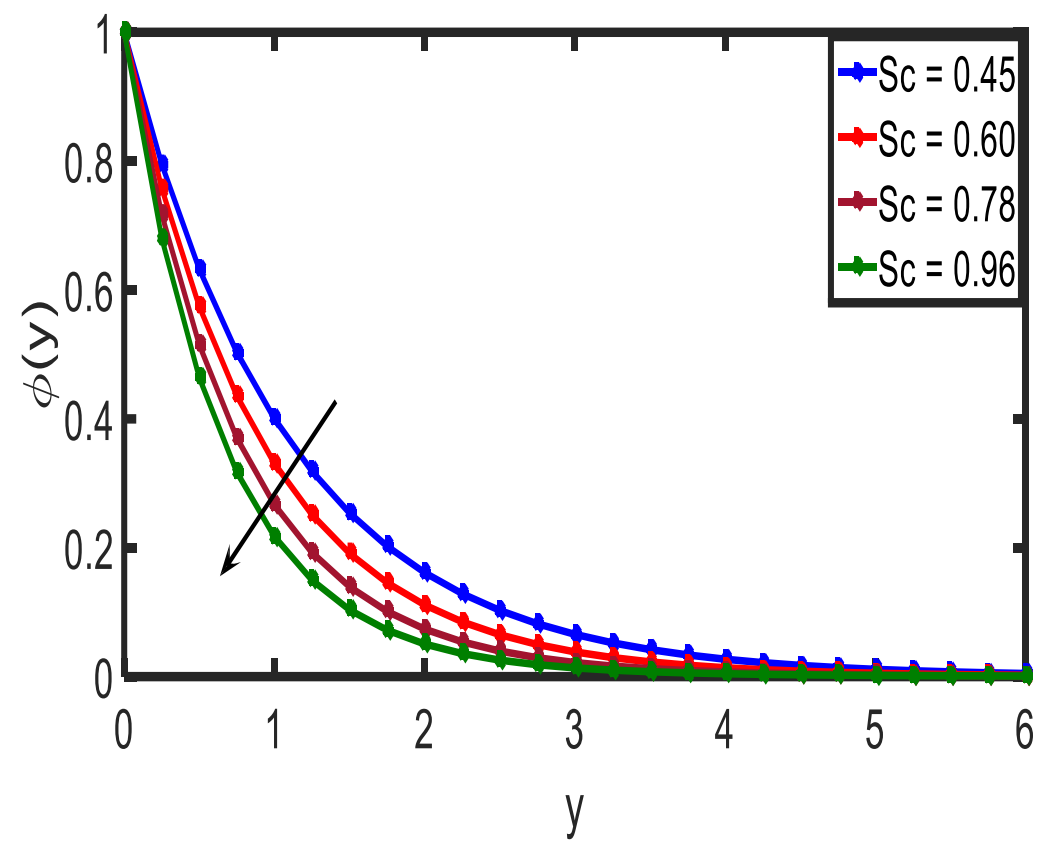

Fig.12 Variations of Sc on concentration distribution

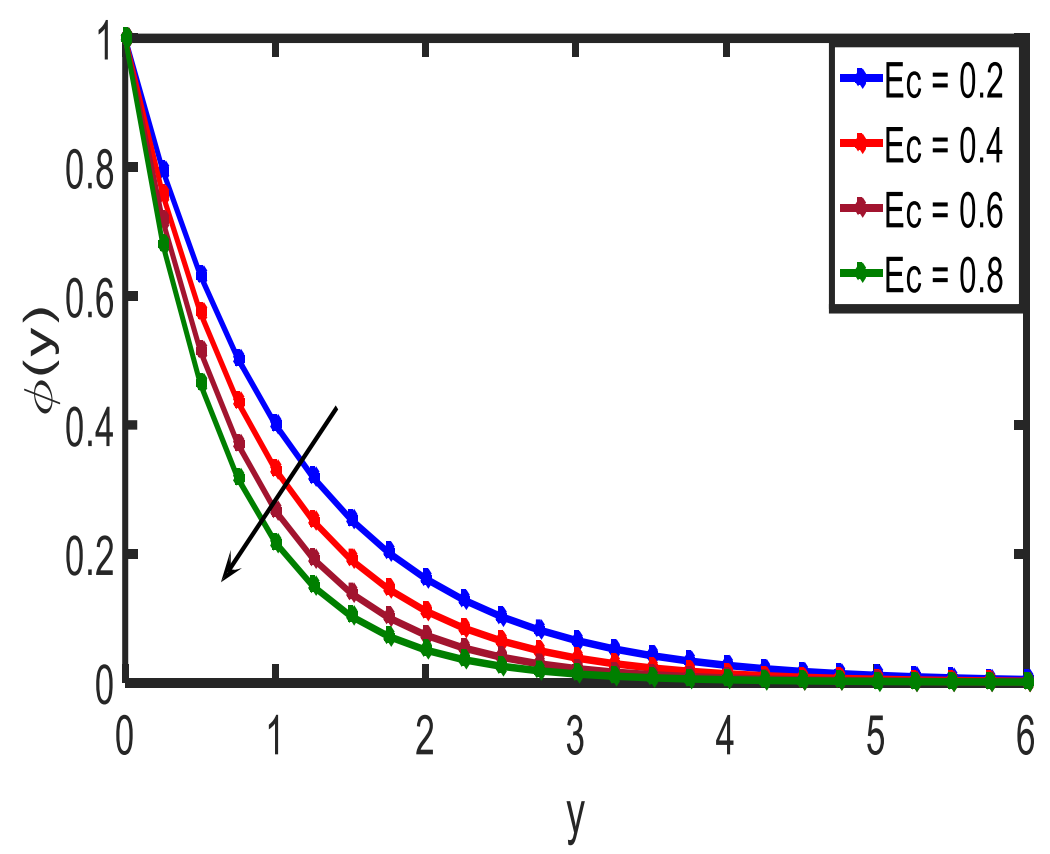

Fig.13 Variations of Ec on concentration distribution

the effect of Eckert number. Figure 11 shows the pattern of temperature for Prandtl number Pr. Physically, as Pr decreases, thermal boundary layer increases hence the raise in the Pr leads to reduction in the temperature. This explanation gives lower Pr value has more consistent temperature profile on thermal boundary layer transversely when contrasted to greater Pr value. It happens when slighter estimations of Pr are similar to enhancing thermal conductivity. Hence, heat is accomplished to diffuse away as of the heated plate more swiftly 
Dharmaiah et al.

International Journal of Thermofluid Science and Technology (2020), Volume 7, Issue 1, Paper No. 20070103

differentiate to greater estimations of Pr. Figure 12 depicted the impacts of the Sc on concentration components. As the Sc enhances, the concentration reduces. The concentration

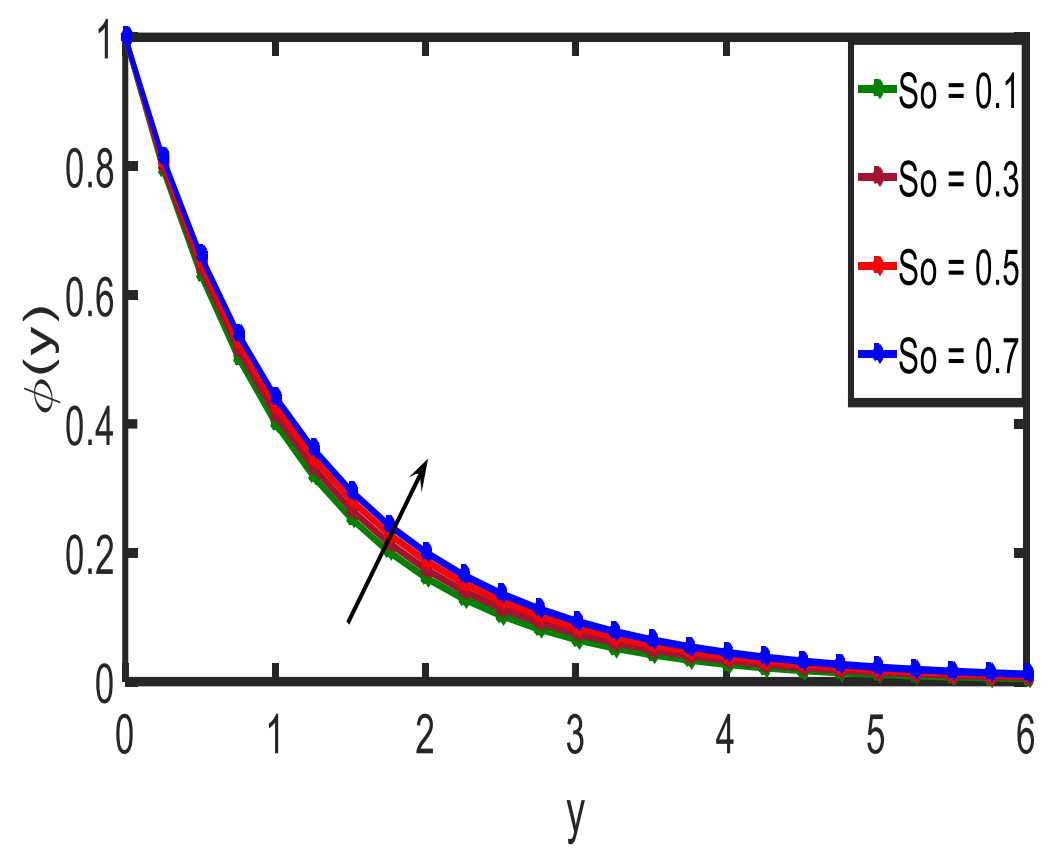

Fig.14 Variations of So on concentration distribution

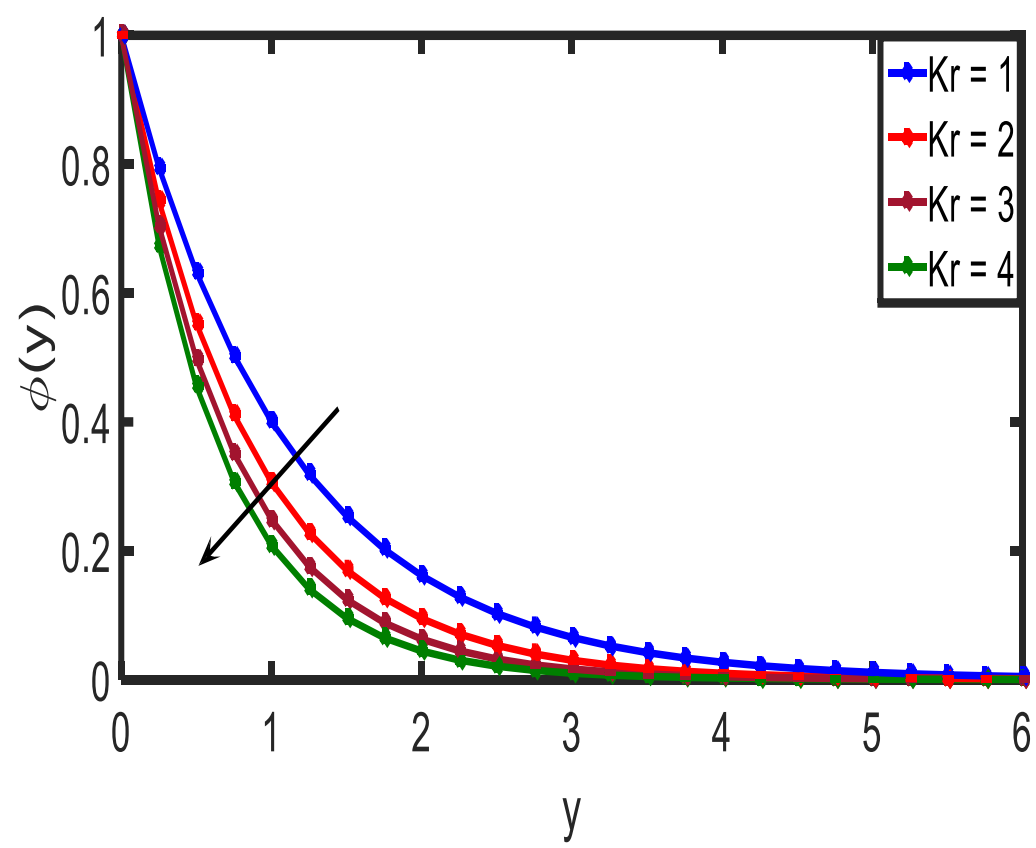

Fig.15 Variations of $\mathrm{Kr}$ on concentration distribution

buoyancy effects to reduce giving way a lessening in the fluid velocity occurred. The reductions on both concentration and velocity components are associated by synchronized reductions in respective boundary layers. Variations of Ec on concentration are displayed in Fig. 13. As can be seen, concentrations profiles reduce due to the effect of Ec. Figure 14 illustrate the impact of So on concentration components. Concentration profiles rises and distinctively with an enhancement of So. Fig. 15 shows the result of the concentration 
Dharmaiah et al.

International Journal of Thermofluid Science and Technology (2020), Volume 7, Issue 1, Paper No. 20070103

distribution for distinct estimations of $\mathrm{Kr}$. As can be seen, the concentration components fall off with the rise of $\mathrm{Kr}$.

Table.1 Variations of unusual physical parameters on skin friction

\begin{tabular}{|c|c|c|c|c|c|c|c|c|c|c|c|}
\hline $\mathbf{K}$ & $\mathbf{M}$ & $\alpha$ & $\mathbf{m}$ & $\xi$ & Ec & Pr & $\mathbf{K r}$ & So & $\mathbf{Q}$ & $\begin{array}{c}\tau \\
\text { (cooled } \\
\text { plate) }\end{array}$ & $\begin{array}{c}\tau \\
\text { (heated } \\
\text { plate) }\end{array}$ \\
\hline $\begin{array}{l}0.1 \\
0.2 \\
0.3 \\
0.4\end{array}$ & & & & & & & & & & $\begin{array}{l}0.8617 \\
1.1548 \\
1.3547 \\
1.5073\end{array}$ & $\begin{array}{l}-0.8350 \\
-1.1211 \\
-1.3173 \\
-1.4676\end{array}$ \\
\hline & $\begin{array}{l}0.1 \\
0.2 \\
0.3 \\
0.4\end{array}$ & & & & & & & & & $\begin{array}{l}1.6838 \\
1.6768 \\
1.6653 \\
1.6497\end{array}$ & $\begin{array}{l}-1.6422 \\
-1.6353 \\
-1.6239 \\
-1.6085\end{array}$ \\
\hline & & $\begin{array}{c}0 \\
\pi / 6 \\
\pi / 4 \\
\pi / 3\end{array}$ & & & & & & & & $\begin{array}{l}3.2573 \\
2.8242 \\
2.3072 \\
1.6303\end{array}$ & $\begin{array}{l}-3.0929 \\
-2.7009 \\
-2.2250 \\
-1.5892\end{array}$ \\
\hline & & & $\begin{array}{l}0.2 \\
0.3 \\
0.4 \\
0.5\end{array}$ & & & & & & & $\begin{array}{l}1.6287 \\
1.6258 \\
1.6212 \\
1.6141\end{array}$ & $\begin{array}{l}-1.5875 \\
-1.5845 \\
-1.5796 \\
-1.5719\end{array}$ \\
\hline & & & & $\begin{array}{c}0 \\
\pi / 6 \\
\pi / 4 \\
\pi / 3\end{array}$ & & & & & & $\begin{array}{l}1.6861 \\
1.6668 \\
1.6483 \\
1.6303\end{array}$ & $\begin{array}{l}-1.6446 \\
-1.6254 \\
-1.6070 \\
-1.5892\end{array}$ \\
\hline & & & & & $\begin{array}{l}0.1 \\
0.2 \\
0.3 \\
0.4\end{array}$ & & & & & $\begin{array}{l}1.7485 \\
1.8798 \\
2.0111 \\
2.1424\end{array}$ & $\begin{array}{l}-1.3376 \\
-1.0581 \\
-0.7785 \\
-0.4990\end{array}$ \\
\hline & & & & & & $\begin{array}{l}0.71 \\
0.81 \\
0.91 \\
1.01\end{array}$ & & & & $\begin{array}{l}1.6303 \\
1.5960 \\
1.5665 \\
1.5419 \\
\end{array}$ & $\begin{array}{l}-1.5892 \\
-1.5541 \\
-1.5200 \\
-1.4681 \\
\end{array}$ \\
\hline & & & & & & & $\begin{array}{l}0.1 \\
0.3 \\
0.5 \\
0.7\end{array}$ & & & $\begin{array}{l}1.9135 \\
1.9123 \\
1.9111 \\
1.8708 \\
\end{array}$ & $\begin{array}{l}-1.8390 \\
-1.7084 \\
-1.6751 \\
-1.6375 \\
\end{array}$ \\
\hline & & & & & & & & $\begin{array}{l}0.2 \\
0.3 \\
0.4 \\
0.5\end{array}$ & & $\begin{array}{l}1.9313 \\
1.9491 \\
1.9671 \\
1.9858\end{array}$ & $\begin{array}{l}-1.9087 \\
-1.9888 \\
-2.0807 \\
-2.1857\end{array}$ \\
\hline & & & & & & & & & $\begin{array}{l}1 \\
2 \\
3 \\
4\end{array}$ & $\begin{array}{l}1.8217 \\
1.7093 \\
1.6381 \\
1.5887\end{array}$ & $\begin{array}{l}-1.8127 \\
-1.7095 \\
-1.6398 \\
-1.5905\end{array}$ \\
\hline
\end{tabular}


Table.2 Variations of unusual physical parameters on Nusselt number

\begin{tabular}{|c|c|c|c|c|c|c|c|}
\hline Sc & $\mathbf{K r}$ & So & $\mathbf{P r}$ & Ec & $\mathbf{Q}$ & $\mathbf{M}$ & $\mathbf{N u}$ \\
\hline $\begin{array}{l}0.45 \\
0.60 \\
0.78 \\
0.96\end{array}$ & & & & & & & $\begin{array}{l}0.5867 \\
0.5872 \\
0.5876 \\
0.5878\end{array}$ \\
\hline & $\begin{array}{l}0.1 \\
0.2 \\
0.3 \\
0.4\end{array}$ & & & & & & $\begin{array}{l}0.5847 \\
0.5852 \\
0.5856 \\
0.5858\end{array}$ \\
\hline & & $\begin{array}{l}1 \\
2 \\
3 \\
4\end{array}$ & & & & & $\begin{array}{l}0.5862 \\
0.5855 \\
0.5848 \\
0.5839\end{array}$ \\
\hline & & & $\begin{array}{l}1 \\
2 \\
3 \\
4\end{array}$ & & & & $\begin{array}{l}0.8841 \\
1.8899 \\
2.8906 \\
3.8902 \\
\end{array}$ \\
\hline & & & & $\begin{array}{l}0.1 \\
0.2 \\
0.3 \\
0.4\end{array}$ & & & $\begin{array}{l}0.5612 \\
0.5329 \\
0.5046 \\
0.4763\end{array}$ \\
\hline & & & & & $\begin{array}{l}1 \\
2 \\
3 \\
4\end{array}$ & & $\begin{array}{l}0.3541 \\
0.3546 \\
0.3548 \\
0.3549\end{array}$ \\
\hline & & & & & & $\begin{array}{l}1 \\
2 \\
3 \\
4\end{array}$ & $\begin{array}{l}0.5869 \\
0.5873 \\
0.5877 \\
0.5881\end{array}$ \\
\hline
\end{tabular}

It represents the difference of concentration and temperatures (buoyancy effects) are significant.

Table 1 exhibits calculated numericals of skin-friction for distinct values like Permeability parameter $(\mathrm{K})$, Magnetic field parameter $(\mathrm{M})$, angle of inclination $(\alpha)$, Hall parameter $(\mathrm{m})$, aligned angle $(\xi)$, Eckert number $(\mathrm{Ec})$, Prandtl number (Pr), Chemical reaction parameter $(\mathrm{Kr})$, Soret parameter $(\mathrm{So})$ and Heat generation parameter $(\mathrm{Q})$ respectively. From table 1, the flow on cooled plate, the skin-friction enhances with rising of K, Ec and So while the skin-friction falls with rising of $\mathrm{M}, \alpha, \mathrm{m}, \xi, \mathrm{Pr}, \mathrm{Kr}$ and Q. Likewise, It is seen that, the flow on heated plate, the skin-friction enhances with rising of $\mathrm{M}, \alpha, \mathrm{m}, \xi, \mathrm{Ec}, \mathrm{Pr}, \mathrm{Kr}$ and $\mathrm{Q}$ while the skin-friction falls with rising of $\mathrm{K}$ and So. Nusselt number $\mathrm{Nu}$, which estimates the rate of heat transfer at the plate $\mathrm{y}=0$, is publicized in table 2 for unusual values of Schmidt number Sc, Soret parameter So, 
Dharmaiah et al.

International Journal of Thermofluid Science and Technology (2020), Volume 7, Issue 1, Paper No. 20070103

Chemical reaction parameter Kr, Prandtl number Pr, Eckert number Ec, Heat generation parameter $\mathrm{Q}$ and Magnetic field parameter $\mathrm{M}$ respectively. The $\mathrm{Nu}$ rises with enhancing $\mathrm{Sc}$, $\mathrm{Kr}, \mathrm{Pr}, \mathrm{Q}$ and M. Also Nusselt number decreases as So and Ec increases.

Table.3 Variations of unusual physical parameters on Sherwood number

\begin{tabular}{|c|c|c|c|c|c|c|}
\hline Sc & $\mathbf{K r}$ & So & Pr & Ec & $\mathbf{Q}$ & Sh \\
\hline 0.45 & & & & & & 0.9182 \\
\hline 0.60 & & & & & & 1.1125 \\
\hline 0.78 & & & & & & 1.3330 \\
\hline \multirow[t]{21}{*}{0.96} & & & & & & 1.5451 \\
\hline & 0.1 & & & & & 0.5120 \\
\hline & 0.2 & & & & & 0.5748 \\
\hline & 0.3 & & & & & 0.6363 \\
\hline & 0.4 & & & & & 0.6869 \\
\hline & & 1 & & & & 0.7858 \\
\hline & & 2 & & & & 0.6299 \\
\hline & & 3 & & & & 0.4623 \\
\hline & & 4 & & & & 0.2808 \\
\hline & & & 1 & & & 0.9065 \\
\hline & & & 2 & & & 0.8750 \\
\hline & & & 3 & & & 0.8327 \\
\hline & & & 4 & & & 0.8415 \\
\hline & & & & 0.1 & & 0.9207 \\
\hline & & & & 0.2 & & 0.9234 \\
\hline & & & & 0.3 & & 0.9261 \\
\hline & & & & 0.4 & & 0.9288 \\
\hline & & & & & 0.1 & 0.9182 \\
\hline & & & & & 0.2 & 0.9262 \\
\hline & & & & & 0.3 & 0.9274 \\
\hline & & & & & 0.4 & 0.9283 \\
\hline
\end{tabular}

Sherwood number Sh, which estimates the rate of mass transfer at the plate $\mathrm{y}=0$, is publicized in table 3 for unusual values of Schmidt number Sc, Chemical reaction parameter Kr, Soret parameter So, Prandtl number Pr, Eckert number Ec and Heat generation parameter Q respectively. Sherwood rises with rising values of $\mathrm{Kr}, \mathrm{Ec}, \mathrm{Sc}$ and $\mathrm{Q}$ and falls with rising values of So, Pr was observed. For the validity of our work we have compared our results with the existing results of Reddy et al. [28] in the absence of inclined angle, aligned and hall current, porous medium, Ohmic heating and heat source. Our result appears to be in excellent agreement with the existing results.

\section{Conclusion}

In the present study, the influence of hall current, aligned magnetic, thermophoresis, chemical reaction and heat source MHD dissipative joint flow convective and heat-mass transfer on an inclined plate embedded in permeable medium was considered. From the solutions cited in the preceding section and from the results and discussion, the subsequent 
Dharmaiah et al.

International Journal of Thermofluid Science and Technology (2020), Volume 7, Issue 1, Paper No. 20070103

conclusions are arrived. There is a considerable effect of heat generation parameter $\mathrm{Q}$ on the velocity. It is found that on introducing the generative chemical reaction species concentration decreases significantly. The effect of Prandtl number decreases the temperature profiles whereas the temperature increase with the increasing values of radiation parameter. The soret effect in concentration is decrease with increase where as in the velocity profile soret effect is increases with the decrease in the profile. The effects of aligned magnetic parameter, heat source and chemical reaction parameter significant in the velocity field and the behaviours of the profiles are noticed similar in all the cases. Concentration profiles are decreasing with the increasing values of Schimidt number and chemical reaction parameter. The enhancement of Prandtl number reveals the rising trend of shearing stress in case of heated plate but the reverse tendency is observed for cooled surface. The effect of Ec on Sherwood number is very significant.

\section{References}

[1] I. Pop, The effect of hall currents on hydromagnetic flow near an accelerated plate. J Math Phys Sci. 5 (1971) 375-85.

[2] M. Veera Krishna, B.V. Swarnalathamma, Ali J. Chamkha, Investigations of soret, joule and hall effects on mhd rotating mixed convective flow past an infinite vertical porous plate. Journal of Ocean Engineering and Science 4 (2019) 263-275.

[3] M. Veera Krishna, Ali J. Chamkha. Hall and ion slip effects on MHD rotating boundary layer flow of nanofluid past an infinite vertical plate embedded in a porous medium. Results in Physics 15 (2019) 102652.

[4] M. K. Nayak, HHR impact on 3D radiative stretched flow of $\mathrm{Cu}-\mathrm{H}_{2} \mathrm{O}$ nanofluid influenced by variable magnetic field and convective boundary condition. International Journal of Thermofluid Science and Technology 6 (2019) 19060202.

[5] Jitendra Kumar Singh, Gauri Shenkar Seth, Pratima Rohidas, Impacts of time varying wall temperature and concentration on MHD free convective flow of a rotating fluid due to moving free-stream with hall and ion-slip currents, International Journal of Thermofluid Science and Technology 6 (2019) 19060301.

[6] H. Vaidya, K.V. Prasad, K. Vajravelu, Chiu-On Ng, S. Nadeem, U.B.Vishwanatha, The effects of thermo capillarity on the thin film flow of mhd ucm fluid over an unsteady elastic surface with convective boundary conditions. International Journal of Thermofluid Science and Technology 6 (2019) 19060303.

[7] C.H. Chen, Combined effects of Joule heating and viscous dissipation on Magnetohydrodynamic flow past a permeable, stretching surface with free convection and radiative heat transfer. Journal of Heat Transfer 132 (2010) 1-5.

[8] S. Siva Reddy and R Srinivasa Raju, Soret effect on unsteady MHD free convective flow past a semi infinite vertical plate in the presence of viscous dissipation. International Journal for computational methods in engineering Science and Mechanics, 16 (2015) 132-141.

[9] P.V. Satyanarayana, D.Ch. Kesavaiah, S. Venkataramana, Viscous dissipation and thermal radiation effects on Unsteady MHD convection flow past a semi infinite vertical permeable moving porous plate. IJMA 2 (2011) 476-487. 
Dharmaiah et al.

International Journal of Thermofluid Science and Technology (2020), Volume 7, Issue 1, Paper No. 20070103

[10] G.Dharmaiah, Ali. J.Chamkha, N.Vedavathi, K.S. Balamurugan, Viscous dissipation effect on transient aligned magnetic free convective flow past and inclined moving plate. Frontiers in Heat and Mass Transfer 12 (2019) 1-11.

[11] A.J. Chamkha, S.E.Ahmed, Similarity solution for unsteady MHD flow near a stagnation point of a three dimensional porous body with heat and mass transfer, heat generation/ absorption and chemical reaction. J Appl Fluid Mech. 4 (2011) 87-94.

[12] F.M.Hady, R.A.Mohamed, A. Mahdy, MHD free convection flow along a vertical wavy surface with heat generation or absorption effect. Int Commun. Heat Mass Transfer, 33 (2006) 253-63.

[13] V.R. Ravikumar, M.C.Raju, G.S.S.Raju, Heat and mass transfer effects on MHD flow of viscous fluid through non-homogeneous porous medium in presence of temperature dependent heat source. Int J Contemp Math Sci. 7 (2012) 1597-04.

[14] M. Turkyilmazoglu and I. Pop, Soret and heat source effects on the unsteady radiative MHD free convection flow from an impulsively started infinite vertical plate. International Journal of Heat and Mass Transfer 55 (2012) 7635-7644.

[15] M. Gnaneswara Reddy, Effects of thermophoresis, viscous dissipation and joule heating on steady MHD heat and mass transfer flow over an inclined radiative isothermal permeable surface with variable thermal conductivity. Int J Heat Tech. 30 (2012) 99-110.

[16] S. Jayaraj, Thermophoresis in laminar flow over cold inclined plates with variable properties. Journal of Heat and Mass Transfer. 30 (1995) 167-173.

[17] M. VeeraKrishna, Hall effects on MHD flow of a visco-elastic fluid through a porous medium over an infinite oscillating porous plate with heat source and chemical reaction. International J. Computer Aided Engineering and Technology (2017). (In press)

[18] R. Kandasamy,I. Muhaimin, H. Salim, Lie group analysis for the effect of temperature - dependent fluid viscosity with thermophoresis and chemical reaction on MHD free convective heat and mass transfer overa porous stretching surface in the presence of heat source / sink. Comm. Nonlinear Sci. Num. Simul. 15 (2010) 21092123.

[19] D. Pal, B. Talukdar, Perturbation analysis of unsteady magnetohydrodynamic convective heat and mass transfer in a boundary layer slip flow past a vertical permeable plate with thermal radiation and chemical reaction. Commun. Nonlinear Sci. Numer. Simul. 15 (2010) 1813-1830.

[20] Ch.BabyRani, K.Ramaprasad, K.S.Balamurugan, G. Dharmaiah, Mhd transient free convection aligned magnetic and chemically reactive flow past a porous inclined plate with radiation and temperature gradient dependent heat source in slip flow regime. IOSR Journal of Mathematics 13 (2017) 34-45.

[21] K.S. Balamurugan, J.L. Ramaprasad, G.Dharmaiah, V.C.C. Raju, Influence of radiation absorption, viscous and joules dissipation on mhd free convection chemically reactive and radiative flow in a moving inclined porous plate with temperature dependent heat source. International Refereed Journal of Engineering and Science 5 (2016) 20-31.

[22] M. J. Uddin, A. K. M. Fazlul Hoque, M. M. Rahman , K. Vajravelu, Numerical simulation of convective heat transport within the nanofluid filled vertical tube of plain and uneven side walls. International Journal of Thermofluid Science and Technology 6 (2019) 19060101. 
Dharmaiah et al.

International Journal of Thermofluid Science and Technology (2020), Volume 7, Issue 1, Paper No. 20070103

[23] P.C.Severno, Marques, Antonio Campo, Finite strip method applied to steady heat conduction and thermal radiation in a planar slab: absorbing-emitting gray material and parallel diffuse surfaces. International Journal of Thermofluid Science and Technology, 6 (2019) 19060102.

[24] G. Manjunatha, C. Rajashekhar, K. V. Prasad, Hanumesh Vaidya, Saraswati, Peristaltic flow of a Jeffery fluid over a porous conduit in the presence of variable liquid properties and convective boundary conditions. International Journal of Thermofluid Science and Technology 6 (2019) 19060201.

[25] M. K. Nayak, A. K. Abdul Hakeem, B. Ganga, Influence of non-uniform heat source/sink and variable viscosity on mixed convection flow of third grade nanofluid over an inclined stretched Riga plate. International Journal of Thermofluid Science and Technology 6 (2019) 19060401.

[26] B. Shankar Goud, B. Suresh Babu , M.N. Raja Shekar, G.Srinivas, Mass Transfer Effects on MHD Flow through Porous Medium past an Exponentially Accelerated Inclined Plate with Variable Temperature and Thermal Radiation. International Journal of Thermofluid Science and Technology 6 (2019) 19060402.

[27] J.L.Ramprasad, K.S.Balamurugan, G. Dharmaiah, Unsteady Mhd Convective Heat And Mass Transfer Flow Past An Inclined Moving Surface With Heat Absorption. JP Journal of Heat and Mass Transfer 13 (2016) 33-51.

[28] N. A. Reddy, S.V.K. Varma, M.C. Raju, Thermo-diffusion and chemical effects with simultaneous thermal and mass diffusion in MHD mixed convection flow with ohmic heating. J Naval Architect Mar Eng. 6 (2009) 84-93.

[29] T.G. Cowling, Magnetohydrodynamics, Interscience Publishers, New York (1957). 